\title{
Technology, Ecology, Autonomy, and the State
}

\author{
Dick G. A. Koelega \\ University of Twente
}

\section{Introduction}

Modern technology plays a major role in the process of deterioration of our natural environment. The delicate web of life in the soil of farmlands is destroyed by pesticides, huge hydroelectricity reservoirs inundate large areas of pristine nature, air and water are polluted by the output of combustion engines, etc. ${ }^{1}$

Technology, ${ }^{2}$ of course, is not the only cause. Other ${ }^{3}$ contributors are, for instance, our economic system, our specific culture, as well as the private activities of people. The issue of who and what causes the environmental problems, which is famous for its complexity, however, is not the subject of this paper. ${ }^{4}$ I want to concentrate on a related, but more limited, issue, viz. the role of the state in controlling ${ }^{5}$ the process of development, diffusion, and use of technology, in particular its role in preventing environmental deterioration. Of course, the state is not the only entity to be held responsible here. Industries, scientists, farmers, consumers, and others have a task too. But the natural environment cannot be defended by initiatives of these agents alone. The state ${ }^{6}$ also has an important role to play. ${ }^{7}$ For instance, it can enact new criminal laws and prohibitions, grant or withhold licenses to industries, control peoples' activities, etc. The question of when such behavior of the state is legitimate is a subject for political philosophy. I will here focus on the liberal political theory, a theory which is still very influential today. ${ }^{8}$

\section{Liberalism and the Preservation of Nature}

Liberal political philosophy, or liberalism as I will call it for reasons of simplicity, ${ }^{9}$ has made important contributions to the theory of the role of the state in modern society. For instance with respect to the moral limits to the criminal law (Feinberg, 1984, 1985, 1986, 1987) or to the concept of a just society (Rawls, 1973). However, it has paid little attention to the role of the state in coping with another important social and political problem, viz. the environmental crisis. In fact it has erected, at least, two large obstacles for state action in this area, viz., anti-paternalism and anti-perfectionism. Anti-paternalism means that state restrictions on a person's liberty "which are justified exclusively by consideration for that person's own good or welfare, and which are carried out either against his present will ... or against his prior commitment" (Arneson, 1980, p. 471) are not allowed, because people have the fundamental right to decide for themselves what to do and what to think. Anti-perfectionism means that "implementation and promotion of ideals of the good life, though maybe worthy in themselves, are not a legitimate matter for state actions" (Raz, 1986, p. 110). These should be neutral with regard to such ideals. The central task of the state therefore is to enable people to live an autonomous life. Respect for the autonomy of individual citizens is the crucial liberal value here.

This does not mean that liberalism never allows state restrictions on individual activities that damage nonhuman nature. There are (at least) two possible liberal arguments for such policies (Musschenga, 1991, p.164), which can be summarized in two principles. First, the principle of social justice, which says that all people should be equally defended from being harmed. Damage to health through polluted air or chemically contaminated food or water counts as harm in this respect. Secondly, the principle of "intergenerational justice" (Achterberg, 1991, p. 147), which says that we have to leave the earth to future generations in the same condition as we inherited it 
from our ancestors, and therefore we may not, for instance, cause widespread desertification or loss of species.

These two liberal principles, however, are in two ways limited in scope.$^{10}$ First, they primarily focus on the interests of human beings. They legitimize state restrictions only in cases where human beings are beings harmed by environ- mental degradation. This has led people to accuse liberalism of "anthropocentrism" (e.g., Naess, 1989). That issue, however, will not be discussed here. Secondly, they define "harm" quite narrowly, for example, as threats to "welfare interests" (Feinberg, 1984, p. 7) or as damage to "primary goods" (Rawls, 1973, p. 84).

As a result they do not allow state restrictions on human activities which do not harm human beings. However, one can say that many of these harmless actions still are harmful to nature. The question I will address in this paper is whether there are other liberal arguments which are in favor of state action to preserve a greater part of nature. For that reason I will look at an alternative liberal perspective. One which is propagated, for instance, by Raz (1986). Raz, for instance, claims that the state should provide and protect a rich plurality of social and cultural life options, because these are part of the necessary conditions for people who want to become autonomous persons. Raz, like other liberals, puts autonomy in the center, but his argument transcends the two former liberal arguments in scope, because it aims to protect more than just the welfare interests or primary goods of people; that is, it protects ways of life as well. The interesting questions for us, of course, then are: Can ecological goods, like pristine natural areas, rich biodiversity, and beautiful cultural landscapes also be counted as necessary conditions for autonomy? And, if so, does that mean that the state has a duty to provide and defend these ecological goods, and, if necessary, to restrict the liberty of individual people and organizations which harm these goods?

Until now, mainstream liberalism was not in favor of such policies, or at least it had not shown much sympathy with them. As a result of the dominance of this theory in our society, many technological developments which threaten ecological goods are left almost uncontrolled and unrestricted. This leads to the paradoxical situation that modern liberal theory seems to legitimize a process which is harmful to the very object it tries to preserve, that is, the personal autonomy of people. In this paper I want to investigate whether liberal theory can be revised in such a way that it also legitimizes state interference with respect to aspects and (side) effects of technological developments that the predominant version of liberalism leaves untouched. And especially whether the state (among others) can be made responsible for ecological changes which do not "harm" (in the definition of liberals) people directly. In my view, the case of the Inuit people in Canada, which I will describe below ${ }^{11}$ is an example of such an effect. First of all I will look briefly at the meaning of "autonomy." Then I will discuss the "necessary conditions" for an autonomous life and address the question if (and to what extent) the state should supply people with these conditions.

\section{Autonomy}

Most writers on the subject of autonomy agree that autonomy is a fuzzy and complex concept. Many have tried to work out a clear definition of the concept. Some even have tried to develop a theory of autonomy, ${ }^{12}$ but no one has been really successful in this endeavor so far (Christman, 1988, pp. 109-112). This is remarkable because the concept has gained such a high standing in our society. ${ }^{13}$

As far as I can see the following elements are central to its meaning. ${ }^{14}$ First autonomy means freedom from external ${ }^{15}$ as well as internal oppressive forces. Autonomy is self-government, is 
the freedom to decide for oneself and not to be manipulated by either a social institution (such as the state or the church) or psychological constraints (such as desires, passions, etc.). An autonomous person, in other words is "sovereign" and has the capacity to be self-mastering and to choose for himself his life-plan and his moral maxims. There is also an element of self-creation in it, the capacity for self-determination which gives man his dignity and authenticity. It is this dignity of man which the state, as well as other social institutions, has to respect.

Controversy exists, among others, about the question whether autonomy is a purely procedural value (a capacity needed for the realization of other, more important values people hold), or whether it is a substantial value itself; that is, whether an autonomous life is the most valuable life there is. Another controversy centers around the question whether the ideal of an autonomous person necessarily implies an "atomistic" or "purely individualistic" view of man, i.e., a view of man with no ties or relations to his society or the community in which he lives. Some critics of liberalism think liberalism is in favor of the latter view. While man, according to them, is an inherently social being, they oppose the ideal of autonomy altogether (Sandel, 1982). There are many liberal writers, however, who also stress that man can become a truly autonomous person only in a close relation with his social and cultural environment, because this very environment provides important ingredients and conditions for his becoming an autonomous person. ${ }^{16}$

Notwithstanding the controversies and conceptual fuzziness, autonomy is one of the most highly valued ideals in our society. And it is in particular the aim of liberal political philosophy to realize and defend that very ideal.

However, autonomy is not something that comes out of the blue. People only become autonomous persons if the necessary conditions ${ }^{17}$ have been fulfilled. The important question then of course is: Which conditions are necessary for an autonomous life?

\section{Conditions for Autonomy and the Role of the State}

Liberals disagree with each other on the question regarding conditions necessary for an autonomous life. This disagreement also leads to different views on the role of the state. I will briefly sketch the views of three liberals on these issues. First the view of Rawls as a representative of what one could call "main- stream liberalism." Next, the views of Raz and Kymlicka, who represent a group of liberals who want to partly revise liberal theory.

Rawls (1973) holds that the necessary conditions for autonomy are what he calls "primary goods." Primary goods are, as he puts it, "of use for the realization of man's self" (p. 84). With more of these goods "man can generally be assured of greater success in carrying out his intentions and in advancing his long-term plan of life" (p. 92). Primary goods are "necessary means whatever plan of life one chooses" (p. 93).

He distinguishes between social primary goods and natural primary goods. Social primary goods are "basic social rights and liberties, powers and opportunities, income and wealth" (p. 62). ${ }^{18}$ Natural primary goods are, for example, "health, vigor, intelligence and imagination" (p. 62).

Rawls holds that the state only has a duty to take care that all citizens equally enjoy the social primary goods (Rawls, 1973, pp. 90-95). The state has no duty to provide natural primary goods to its citizens, although he acknowledges that the possession of these goods, as well as of selfrespect (which is also a primary good), is "partly influenced by the basic structure of society"; but, "they are not directly under the state control" (Rawls, 1973, p. 62). It need not surprise us then that Rawls also sees no task for the state to preserve other, non-primary goods, such as indigenous cultures or beautiful natural environments. Rawls agrees that it may sometimes be 
lamented when worthy ways of life and cultural traditions disappear, due to, for instance, the process of modernization - of which the diffusion of modern technology is a part. But he claims that the state has to abstain from interference and that it may not do anything to stop this process. All it has to do is to take care that society is a "well-ordered society"19 (Rawls, 1975, p. 547), because such a society "defines a fair background within which ways of life have a reasonable opportunity to establish themselves. If a conception of the good is unable to endure and gain adherents under the institution of equal freedom and mutual toleration, one must question whether it is a viable conception of the good, and whether its passing is to be regretted" (Rawls, 1975, p. 549). At any rate, these conceptions and ways of life "cannot be upheld by the coercive apparatus of the state" (Rawls, 1975, p. 551).

Raz (1986) believes that, for human beings to be able to lead an autonomous life, more is needed than Rawls suggests. Next to the primary goods mentioned by Rawls, people also need, in the words of Raz, "an adequate range of (life-)options" (p. 373). By this range he means the collection of life-options people can chose from when they mature and gradually become autonomous persons.

Raz, in fact, uses two criteria for adequacy. In my words: a plurality criterion and a quality criterion.

The plurality criterion lies behind his claim that "people should have available to them a rich collection of forms and styles of life" (p. 425) out of which they can freely choose their own conception of the good life. This collection should be richly varied, because, according to Raz, human beings have "various ${ }^{20}$ innate drives. ${ }^{21}$ Therefore, as Raz states, "to be autonomous and to lead an autonomous life, a person must have [various] options which enable him to sustain throughout his life activities which, taken together, exercise all the capacities human beings have an innate drive to exercise" $(\operatorname{Raz} 1986,375) .^{22}$

The quality criterion can be found in his claim that the options should be valuable options. Plurality of options is not enough. The range, for example, should not contain trivial options or options which are horrendous in their consequences; it should include options with both longterm and pervasive consequences, ${ }^{23}$ as well as short term and lesser consequences, and there should be a fair spread between them too. ${ }^{24}$ Also "viable and morally worthy cultures" should be part of the range, for, they too, are necessary conditions of autonomy (p. 423). Cultures he has in mind here are, for instance, cultures of indigenous peoples, immigrant communities, and religious sects. ${ }^{25}$

Raz therefore sees a broader task for the state than Rawls does. It has a duty both to defend threatened minority cultures in order to encourage the flourishing of a plurality of competing cultures (Raz, 1986, 425), as well as to support the preservation of a qualitative range of life options, or, in other words, the state has a duty to support the preservation of a "public culture which main- tains and encourages the cultivation of certain tastes and the undertaking of certain pursuits. A public culture which inculcates respect for the environment, and for its transformation at the hands of past generations, and which cultivates agreeable design and good taste in landscaping and urban planning" (Raz, 1986, pp. 421-422).

Kymlicka (1989), in my view, uses an argument which resembles Raz's plurality argument. ${ }^{26} \mathrm{He}$ says that a pluralistic society with a large variety of subcultures and minorities is what he calls, "the context of choice" (p. 164) which "provides [people] with different ways of life" (p. 164) out of which they can choose the one they like and against which background they become autonomous and authentic persons, and therefore it is a necessary condition for autonomy. The 
state, according to Kymlicka, therefore has to support and defend a pluralistic range of cultural options (Kymlicka, 1989, p. 81).

But next to the plurality argument and quality argument Kymlicka also introduces a third argument for state protection of necessary conditions for autonomy. "Cultural membership," he says, contrary to what Rawls and many other liberals think, is a "primary good" itself (p. 166), because "cultural membership affects our very sense of personal identity" (p. 175), and because "cultural heritage ... [is] a source of emotional security and personal strength" (p. 176). It is "only ${ }^{27}$ through being a member of a rich and secure cultural structure that people can become aware ... of the options available to them and intelligently examine their value" (Kymlicka, 1989, p. 165). In fact, by introducing the idea of cultural membership as a primary good, Kymlicka extends the liberal social justice argument. In a just society the state, according to Kymlicka, therefore is also concerned with the fate of cultural minorities and uses its libertylimiting powers to defend them.

Hence we see that Raz and Kymlicka ascribe to the state a more comprehensive task than Rawls does, due to their broader conception of the conditions which are necessary for people's autonomy. These arguments, however, are primarily aimed at improving the conditions for human happiness. Can such anthropocentric arguments be of help to the preservation of nature? I think they can, because a rich and stimulating natural environment, ${ }^{28}$ in my view is a necessary precondition for the three autonomy enhancing arguments of Raz and Kymlicka, viz. the plurality argument, the quality argument and the extended social justice argument.

My arguments for this view are the following:

1. Many minorities and indigenous cultures Raz and Kymlicka want to preserve, in order to secure the plurality of the "context of choice," are both physically, as well as religiously dependent on their present natural environment. If one wants to save these communities and cultures, one also needs to preserve their natural habitat.

To give an example: Kymlicka argues that the state of Canada should grant special group rights to the Cree and Inuit people in order to enable them to keep their communities and cultures alive. In my view that would not be enough. For the state should also take measures, for instance, to stop Hydro Quebec, the company which is building, and planning to build many more, huge dams for a hydroelectricity project which will flood large parts of the traditional hunting grounds of the these people. ${ }^{29}$

2. Also many of the "qualitative" ways of life Raz wants to preserve are dependent on the availability of a rich and stimulating natural environment. In many of these ways of life nature is important. For example, it is the source or object of what I call "ulterior experiences," i.e., experiences which to many30 people are very important. There is a large variety of such experiences known, it is often difficult to describe them accurately and they are often multiinterpre- table. Some people refer to experiences of unspeakable beauty, others of a fee- ling of relatedness or belonging to nature. Some speak about experiences which made them "transcend" themselves; some say they got new religious insights from that, others new moral meanings. A large number of the indigenous people Kymlicka wants to defend hold nature to be the habitat of their ancestors or gods. "Modern" people speak about getting comfort and inspiration when abiding in beautifully cultivated or natural sceneries. Although we have to be very critical towards such experiences and although maybe quite a lot of them do not make sense (to us!), the fact that many people do value these experiences very highly may not be denied. These experiences are not possible without their object, i.e., a rich and stimulating natural environment. 
So the latter, in a sense, can be considered a necessary condition for autonomy, too.

Of course liberals, like Rawls or Feinberg, will oppose the policies suggested by Raz, Kymlicka and myself, because they consider them to be paternalistic and perfectionistic.

Paternalistic, because such policies seem to stop people, against their will, from destroying goods they do not appreciate themselves now, on the presumption that there may come a time when they will need them as a condition for autonomy.

Perfectionistic, because such policies do not seem to be neutral with regard to private ideals of the good life. On the contrary, they openly promote some particular ideals.

However, these accusations are only partly true. First of all, the policies are not limiting people's freedom for their own good, but for the good of all people, irrespective of age, race, wealth, religion and sex, and living today or in the future. In that they resemble, according to Raz, many other forms of "indirect paternalism" which are well accepted in our liberal society, such as the compulsory wearing of seat belts or safety and quality controls of manufactured goods (Raz, 1986, p. 422). Secondly, and more important, they do not aim at reducing people's range of choice options, as liberals worry paternalism does, but instead they aim at securing a large and adequate variety of life options, which is, as has been argued, a necessary condition for autonomy. Thirdly, the policies are not perfectionistic in the negative sense, as liberals understand that term ${ }^{31}$ either. They do promote an ideal of the good life, that is, that of an autonomous life; but there is a widespread consensus on that ideal in western societies. In fact it is one of the fundamental values of western culture, and it is also the fundamental value that inspires liberals like Rawls and Feinberg. Although substantial in itself, it is impartial and instrumental to many specific ideals of the good life. Raz, Kymlicka and myself thus share with liberals a fundamental respect for personal autonomy.

Some may say the proposals of Raz cum suis show that they are merely conservatives who want to preserve every existing local community, distinctive tradition, or natural setting or species. This is not true. Autonomy does not require the presence of each and every particular option (Raz, 1986, p. 410). Raz, for instance, also makes an exception for cultures which harm their own or other people or those which do not support, or even actively oppress, the ideal of personal autonomy of their members. These do not have to be preserved at all (Raz, 1986, p. 423).$^{32}$ Of course, due to social, economic and technological pro- cesses the range of options, as well as the options themselves are constantly changing. In principle the state has no responsibility to interfere in this process. However, what worries Raz, Kymlicka and myself is that, due to, for instance, uncontrolled technological development, a situation is being created (a) in which the range of options becomes "inadequate" as a condition for autonomy, i.e., too uniform, too superficial, too shallow, etc.; (b) in which the speed of these changes becomes too abrupt; and (c) in which these changes are forced upon people, so that they involuntarily lose their community, their culture, or the natural setting in which they used to live. Such situations do exist already, nowadays and technology plays an important role in creating them.

\section{Conclusion}

My conclusion is that the fear of liberals is not realistic; the autonomy of people will not be threatened by state interference in social processes, like technological developments, if the interference aims at preserving a rich and stimulating natural environment. On the contrary, such state interference is morally justifiable even from a liberal point of view, because its ulterior object is to enable people to lead an autonomous life. 


\section{Notes}

1. It is not possible to give a detailed description here of the various aspects and origins of the environmental crisis. Nor is it possible to discuss the question, put forward lately, whether there is a crisis. Accurate empirical investigations in this field, of course, are necessary. However, I believe that there are already enough indications that we are stuck with serious environmental problems.

2. "Technology" is a slippery term and difficult to define. Definitions vary from a narrow to a broad approach (Hickman, 1991, Winner, 1991). I prefer a broad definition: technology is the social process in which people, governed by specific western values and epistemological methods, and with the help of specific tools of all sorts (instruments, procedures, organizational me- thods, etc.), manipulate and transform their natural, social and cultural environment in order to provide the necessary conditions for their survival and their well-being. Technology, therefore, is not only machines or procedures to perform a special task (I call that technics), but also the social and cultural context within which technics are being developed and applied.

\section{See note 4.}

4. In fact speaking about different and distinguished causes in this context is not adequate at all. Many writers have pointed to the fact that technology, science, the economy, western culture, and the state are intricately interwoven with each other, as are the activities of individual people and various social collectivities; see, e.g., Bijker, Hughes and Pinch (1987), Borgmann (1984), Latour (1987), Westrum (1991), and Winner (1977).

5. The word "controlling" in this context is always problematic. By using it I do not pretend to say that the evolution of technology can simply be steered like a ship or a horse. I only want to indicate that some guidance of the process is possible and needed, although any control of technology by the state is being hampered by the segmentation, complexity, and pluralization of modern society. I therefore do not agree at all with the technological determinists who hold that the process is out of human control.

6. I use the word "state" to refer to all kinds of public authorities and institutions, such as parliaments, governments, courts, and the various kinds of state agencies.

7. It may be remembered here that, in most industrialized countries, the state is already an important stimulator of technological innovation. It spends a lot of money on research and development projects, it carries out innovative technological programs itself, it gives all kinds of logistical support to new techno- logical developments, etc.

8. Many people deny this and say that real politics, be it in Washington, London, Paris or elsewhere, is only governed by lobbyists, shrewd manipulators of political power, public emotions, private and group interests, etc., and that real politics is characterized by negotiations and compromises instead of the sincere application of liberal principles. There may be an element of truth in this view, but it is, in my view an exaggeration. I take it that liberal political theory still is very important, for instance in law courts, in the Supreme Court, and also in political debates on major social, juridical, moral and other issues. Empirical evidence for this thesis, for example, is the ongoing debate in the Netherlands on minority rights or on abortion and euthanasia. I agree that the political debate on environmental issues is not very often framed in liberal terms (Musschenga, 1991). But that omission is exactly what I regret very much. Instead I would like to make a strong plea to make a start with it.

9. The word "liberalism" in the literature is used to describe three related phenomena: (1) liberal political philosophy; (2) liberal economic theory; and (3) a worldview which stresses values such as autonomy, individuality, and equality. I use it here only in the first sense.

10. With this I do not pretend that they are wrong. On the contrary, I think it would be a good thing to further develop liberal thinking with respect to the issue of ecology along these two lines (and maybe others). However, in this paper I want to sketch the contours of a third line of liberal argumentation in favor of policies that preserve our natural environment; i.e., a line which is in favor of "preserving the conditions for our autonomy."

11. The causal relation between technological development, loss of ecological goods, and the threatening of people's autonomy, of course, is a very complicated one. Due to the limited scope of this paper I can only be brief about this relation.

\section{For example, Dworkin (1988).}

13. Personal autonomy became an important value quite late in the history of morality, viz. after the Reformation and in particular since the seven- teenth and eighteenth century; on the history of the concept in moral philosophy, see, e.g., Dworkin (1988), Kuitert (1989), Schneewind (1986). 
14. The literature on the subject has become quite extensive. I rely here mainly on the work of Christman (1988), G. Dworkin (1988), Feinberg (1986, chap. 18), Rawls (1973), and Raz (1986).

15. This fear of manipulation by external powers lies also at the bottom of liberal anti-paternalism.

16. See, for example, Dworkin (1988, pp. 11-12) and Rawls (1973, pp. 522-525).

17. One can think of social, political, psychological, and cultural conditions. As I will try to argue in the next section, it is right to think of ecological or environmental conditions as well.

18. For example, "the right to vote and to be eligible for public office, freedom of speech and assembly, liberty of conscience and freedom of thought" (Rawls, 1973, p. 61).

19. According to Rawls a liberal society is a "well-ordered society."

20. Emphasis mine.

21. For example, "to exercise our bodies, to move around, to stimulate our senses, to engage our imagination and affection, to occupy our mind" (Raz, 1986, p. 375).

22. Behind this lies Raz's anthropology, his view of what a human being is. Psychologists and biologists, of course, may question whether this view is accurate. I cannot go into that discussion here. But I think his view is quite plausible and realistic (at least in relation to western man).

23. "We should be able to choose long term commitments or projects and develop lasting relationships and be able to develop and pursue them by means which we choose" (Raz, 1986, p. 374).

24. ". . in order to make sure that our control extends to all aspects of our lives" (Raz, 1986, p. 374).

25. Raz is aware of the fact that this criterion raises a lot of difficult questions: which cultures, for instance are morally worthy and what is morally worthy? He does not go into these questions very deeply; due to the limited scope of this paper I too have to let this subject rest. For a critique, see Musschenga (1990).

26. He does not say anything about Raz's quality argument, nor does he use such an argument himself.

27. Emphasis mine. Of course, "only" may be a too strong word here. I think it is more reasonable to say that cultural membership is one of the important conditions for autonomy.

28. There is much discussion of the definition of this term, but I cannot go into it here. In brief, by "natural environment" or "nature" (a word I will use as a synonym) I here mean pristine natural areas as well as old cultural landscapes, and both non-human forms of life and non-living nature.

29. See Vandergeest (1991).

30. One can question what is meant by "many." I take it that a considerable number of people have such experiences. I do, many friends of mine do, I guess many members of the growing environmental movement do, and many members of indigenous people do, at least. Of course, it would take a separate research project to prove this proposition. But, in my view, it is not that important whether a large or a small part of the population has such experiences. Because even if only a small number, say one percent of the population, values them it is still a reason to preserve the source of these experiences, i.e., when no one is being harmed by it (as defined by liberals). Next, it may be that such experiences become highly valued by future generations. Where will they have to go when so much of nature has been damaged?

31. See earlier parts of this paper.

32. This position, of course, raises many other difficult questions, but I cannot discuss them here.

\section{Acknowledgements}

I am grateful to Bert Musschenga and Bart Voorzanger for useful comments on an earlier version of this paper. 


\section{References}

Achterberg, W. "Kan de liberale democratie de milieucrisis overleven? Duurzame ontwikkeling tussen neutraliteit en perfectionisme," in Zweers, W., ed., Op zoek naar een ecologische cultuur: Milieufilosofie in de jaren Negentig. Baarn: Ambo, 1991, pp. 129-135.

Arneson, R. J. “Mill versus Paternalism,” Ethics 90 (1980):470-489.

Bijker, W. E., Hughes, T. P., and Pinch, T. J., eds., The Social Construction of Technological Systems: New Directions in the Sociology and History of Technology. Cambridge, Mass.: MIT Press, 1987.

Borgmann, A. Technology and the Character of Contemporary Life. Chicago: University of Chicago Press, 1984.

Christman, J. "Constructing the Inner Citadel: Recent Work on the Concept of Autonomy," Ethics 99 (October 1988): $109-124$

Dworkin, G. The Theory and Practice of Autonomy. Cambridge: Cambridge University Press, 1988.

Feinberg, J. Harm to Others: The Moral Limits of Criminal Law, vol. 1. New York: Oxford University Press, 1984.

Feinberg, J. Offense to Others: The Moral Limits of Criminal Law, vol. 2. New York: Oxford University Press, 1985.

Feinberg, J. Harm to Self: The Moral Limits of Criminal Law, vol. 3. New York: Oxford University Press, 1986.

Feinberg, J. Harmless Wrongdoing: The Moral Limits of Criminal Law, vol. 4. New York: Oxford University Press, 1988.

Hickman, L. A. "Techniques of Discovery: Broad and Narrow Characterizations of Technology," in Pitt, J.C., and Lugo, E., eds., The Technology of Discovery and the Discovery of Technology, Proceedings of the Sixth International Conference of the Society for Philosophy and Technology. Blacksburg, Va.: The Society for Philosophy and Technology, 1991, 127-136.

Kuitert, H. M. Autonomie, een lastige laatkomer in de ethiek. Amsterdam, 1989.

Kymlicka, W. Liberalism, Community and Culture. Oxford: Clarendon Press, 1989.

Latour, B. Science in Action: How to Follow Scientists and Engineers through Society. Cambridge, Mass.: Harvard University Press, 1987.

Musschenga, A. W. "Een liberaal over vrijheid en waardevol leven," Rechtsfilosofie en Rechtstheorie 19 (1990): 19-41.

Musschenga, A. W. "Liberale Neutraliteit en de Rechtvaardiging van Milieubehoud," in Zweers, W., ed., Op zoek naar een Ecologische Cultur: Milieufilosofie in de jaren Negentig. Baarn: Ambo, 1991, pp. 161-169.

Naess, A. Ecology, Community and Lifestyle: Outline of an Ecosophy. Cambridge: Cambridge University Press, 1989.

Rawls, J. A Theory of Justice. Oxford: Oxford University Press, 1973.

Rawls, J. "Fairness to Goodness," Philosophical Review 74 (1975): 548-551.

Raz, J. The Morality of Freedom. Oxford: Clarendon Press, 1986.

Sandel, M. J. Liberalism and the Limits of Justice. Cambridge: Cambridge University Press, 1982.

Schneewind, J. B. "The Use of Autonomy in Ethical Theory," in Heller, T. C., et al., Reconstructing Individualism: Autonomy, Individuality, and the Self in Western Thought. Stanford: Stanford University Press, 1986, pp. 64-75.

Vandergeest, T. "Waterkracht helpt noorden Quebec naar deeeuwige jachtvelden," Milieudefensie 9(1991):26-27.

Westrum, R. Technologies and Society:. The Shaping of People and Things. Belmont, Calif: Wadsworth 1991.

Winner, L. Autonomous Technology: Technics-out-of-Control as a Theme in Political Thought. Cambridge Mass.: MIT Press, 1977.

Winner, L. "Upon Opening the Black Box and Finding It Empty: Social Constructivism and the Philosophy of Technology," in Pitt, J. C., and Lugo, E., eds., The Technology of Discovery and the Discovery of Technology: Proceedings of the Sixth International Conference of The Society for Philosophy and Technology. Blacksburg: SPT, 1991, pp. 503-519. 